\title{
Phosphate removal in agro-industry: pilot and full-scale operational considerations of struvite crystallisation
}

\author{
W. Moerman ${ }^{a}$, M. Carballa ${ }^{b}$, A. Vandekerckhove ${ }^{c}$, D. Derycke ${ }^{d}$ and \\ W. Verstraete ${ }^{\text {b }}$ \\ ${ }^{a}$ Akwadok Hoekstraat 3, 8540 Deerlijk Belgium \\ bLabMET Coupure Links 653, 9000 Gent Belgium \\ ${ }^{\circ}$ Clarebout Potatoes nv Heirweg 26, 8950 Nieuwkerke Belgium \\ ${ }^{\mathrm{d} B i o t i m}$ Antwerpsesteenweg45, 2830 Willebroek Belgium
}

\begin{abstract}
Pilot-scale struvite crystallisation tests using anaerobic effluent from potato processing industries were performed at three different plants. Two plants (P1 \& P2) showed high phosphate removal efficiencies, $89 \pm 3 \%$ and $75 \pm 8 \%$, resulting in final effluent levels of $12 \pm 3 \mathrm{mg} \mathrm{PO}{ }_{4}^{3-}-\mathrm{P} / \mathrm{L}$ and $11 \pm 3 \mathrm{mg} \mathrm{PO}_{4}^{3-}-\mathrm{P} / \mathrm{L}$, respectively. In contrast, poor phosphate removal $(19 \pm 8 \%)$ was obtained at the third location (P3). A noticeable difference in the influent $\mathrm{Ca}^{2+} / \mathrm{PO}_{4}^{3-}-\mathrm{P}$ molar ratio was observed between the test sites, ranging from $0.27 \pm 0.08(\mathrm{P} 1), 0.62 \pm 0.18(\mathrm{P} 2)$ and $0.41 \pm 0.04(\mathrm{P} 3)$. A negative effect on struvite formation occurred when a $\mathrm{Ca}^{2+} / \mathrm{PO}_{4}^{3-}-\mathrm{P}$ molar ratio of $1.25 \pm 0.11$ was obtained after initial $\mathrm{pH}$ increase in the stripper at $\mathrm{P} 3$. A full-scale struvite plant treating $90-110 \mathrm{~m}^{3} / \mathrm{h}$ of anaerobic effluent from a diary industry also showed $\mathrm{Ca}^{2+}$ interference. Initially in this plant, influent phosphate levels ranging from 40 to $45 \mathrm{mg} \mathrm{PO}_{4}^{3-}-\mathrm{P} / \mathrm{L}$ were decreased to below $10 \mathrm{mg} \mathrm{PO}{ }_{4}^{3-}-\mathrm{P} / \mathrm{L}$, but no struvite was produced. A shift in $\mathrm{Ca}^{2+} / \mathrm{PO}_{4}^{3-}-\mathrm{P}$ molar ratio from 2.69 to 1.36 by an increased phosphate concentration resulted in average total phosphorus removal of $78 \pm 7 \%$, corresponding with effluent levels of $14 \pm 4 \mathrm{mg}$ $\mathrm{P}_{\text {total }} / \mathrm{L}\left(9 \pm 3 \mathrm{mg} \mathrm{PO}_{4}^{3-}-\mathrm{P} / \mathrm{L}\right)$. Under these conditions pure spherical struvite pellets of 2-6 $\mathrm{mm}$ were produced.
\end{abstract}

\section{INTRODUCTION}

Although the advantages of anaerobic treatment are obvious, subsequent nutrient removal still remains an important issue. Readily biodegradable organic matter needs to be bypassed towards aerobic post-treatment in order to achieve the final nutrient effluent standards, thus reducing the potential biogas yield and increasing the waste sludge production. Nutrient removal by struvite $\left(\mathrm{MgNH}_{4} \mathrm{PO}_{4} \cdot 6 \mathrm{H}_{2} \mathrm{O}\right)$ or magnesium ammonium phosphate (MAP) precipitation is an interesting alternative approach to address phosphorus removal (von Munch and Barr, 2001; Gonzalez and De Sa, 2007). MAP crystallisation can be applied for several purposes, such as to prevent scaling problems

(C) 2009 The Authors, International Conference on Nutrient Recovery from Wastewater Streams. Edited by Ken Ashley, Don Mavinic and Fred Koch. ISBN: 9781843392323. Published by IWA Publishing, London, UK. 
(Doyle and Parsons, 2004) and to remove phosphate (Battistoni et al., 1997) or nitrogen (Altinbas et al., 2002; Laridi et al., 2005). Recent publications show an increasing interest in struvite precipitation as a technology for phosphorus recovery taking into account the economic impact of increasing energy costs and limited natural phosphorus resources (Durrant et al., 1999; Shu et al., 2006; Carballa et al., 2008; Forrest et al., 2008). Consequently, integration of struvite formation as specific treatment of side-stream wastewaters is becoming a common practise (Caffaz et al., 2008).

Increasing the operational $\mathrm{pH}$ and adjustment of the molar ratios of magnesium, ammonium and phoshate are the most important process parameters in MAP crystallisation (Ohlinger et al., 1998). In addition, presence of calcium has been shown to be determinative for both crystal size and purity (Le Corre et al., 2005; Pastor et al., 2007). When anaerobically processed wastewaters are treated, $\mathrm{pH}$ can be increased by simple air stripping (Williams, 1999). If air stripping does not suffice, additional alkaline reagents must be added. Alkaline addition can be combined with the required magnesium supplementation by using either $\mathrm{MgO}$ or $\mathrm{Mg}(\mathrm{OH})_{2}$ (von Münch and Barr, 2001). Other magnesium sources include magnesium chloride, magnesium sulphate or seawater bittern waste (Li and Zhao, 2002). If ammonium removal is targeted, both magnesium and phosphate have to be supplied. Yet, to minimize reagent use, internal recycling of the magnesium and phosphate is possible by thermal decomposition of the recovered MAP (Stefanowicz et al., 1992; He et al., 2007).

Different pilot and full-scale units using fluidized bed (Ueno and Fujii, 2001; Forrest et al., 2008) or continuously stirred tank reactors (Mangin and Klein, 2004; Laridi et al., 2005) have been operated. Most full-scale struvite plants do treat anaerobic liquor originating from primary and secondary sludge digestion (Ueno and Fujii, 2001; Battistoni et al., 2005; Forrest et al., 2008). This paper describes the successful use of a fairly straightforward stirred tank crystallizer for full-scale phosphate recovery by struvite crystallization treating anaerobic effluent from a dairy processing industry at an average flow rate of $100 \mathrm{~m}^{3} / \mathrm{h}$. It also points out the need of preliminary feasibility tests before full-scale application to exclude excessive calcium interference, which renders this technology inefficient.

\section{MATERIAL AND METHODS}

\section{Pilot plant description}

Figure 1 shows a scheme of the pilot plant used. The anaerobic effluent was continuously fed into the stripper through peristaltic pump 1 . The total volume of the stripper was $180 \mathrm{~L}$ and air was supplied as coarse bubble aeration at $8 \mathrm{~L} / \mathrm{s}$. 
The 200 L-crystallizer was equipped with a 3 blade top entry impeller (impeller diameter/tank diameter $=0.5$ ) and $120^{\circ}$ interval baffles. The crystals were retained by a transient quiescent settling zone. Online control was used to adjust $\mathrm{pH}$ with $29 \% \mathrm{NaOH}$ (pump 2). $\mathrm{MgCl}_{2}$ was used as magnesium source and $\mathrm{Mg}^{2+}$ dosage was controlled by setting the flowrate (pump 3) of $\mathrm{MgCl}_{2}$ solution $(30 \%, v / v)$ according to the influent flowrate. Under steady state conditions, $\mathrm{pH}$ was controlled between 8.50 and 8.70 and an $\mathrm{Mg}^{2+} / \mathrm{PO}_{4}^{3-}-\mathrm{P}$ molar ratio of 1 to 1.2 was maintained. Struvite crystals were removed by intermittent purging.

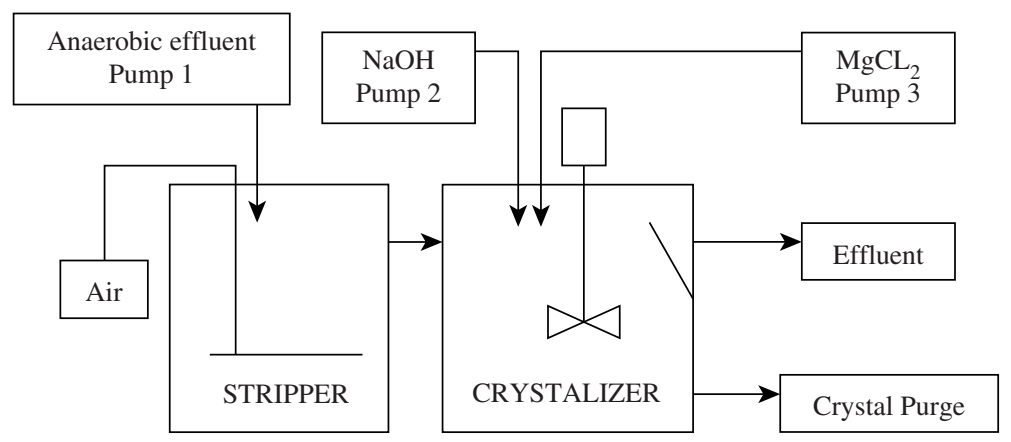

Figure 1. Pilot scale unit used in the struvite crystallisation tests.

Influent and effluent samples were taken 2-3 times a week for ammonium, phosphate and magnesium determinations. Recovered MAP was dried at ambient room temperature to avoid ammonia loss and then used for X-ray diffraction (XRD) analysis.

\section{Anaerobic effluent characteristics}

Pilot-scale tests were performed over a 2-3 month period at 3 different potato processing plants. On average, $5 \mathrm{~m}^{3} /$ day of anaerobic effluent coming from the full-scale upflow anaerobic sludge bed (UASB) reactor was treated in the struvite crystallisation. Table 1 shows the initial characteristics of the 3 different anaerobic effluents used.

\section{Analytical methods}

$\mathrm{pH}$ was measured with a $\mathrm{pH}$ meter (Consort C532). Ammonium was determined colorimetrically with Nessler reagent according to standard methods (APHA, 1992). Phosphate and magnesium were determined using a Metrohm 761 compact ion chromatograph equipped with a conductivity detector and flame atomic absorption spectrometry, respectively. Total phosphorus, dry matter 
content and its mineral fraction were determined according to standard methods (APHA, 1992). XRD analyses were done by using a Siemens D5000 unit equipped with $\mathrm{Cu} \mathrm{K}_{\alpha}$ radiation at $1.54 \AA$.

Table 1. Characteristics of the UASB effluent (influent of struvite pilot plant) of the 3 test sites.

\begin{tabular}{lccc}
\hline & Plant 1 & Plant 2 & Plant 3 \\
\hline $\mathrm{pH}$ range & $7.00-7.45$ & $7.10-7.50$ & $7.00-7.85$ \\
$\mathrm{PO}_{4}^{3-}-\mathrm{P}(\mathrm{mg} / \mathrm{L})$ & $115 \pm 13$ & $43 \pm 7$ & $127 \pm 8$ \\
$\mathrm{NH}_{4}^{+}-\mathrm{N}(\mathrm{mg} / \mathrm{L})$ & $426 \pm 45$ & $208 \pm 27$ & $254 \pm 36$ \\
$\mathrm{Ca}^{2+}(\mathrm{mg} / \mathrm{L})$ & $40 \pm 8$ & $36 \pm 7$ & $65 \pm 7$ \\
$\mathrm{Ca}^{2+} / \mathrm{PO}_{4}^{3-}-\mathrm{P}$ molar ratio & $0.27 \pm 0.08^{\mathrm{a}}$ & $0.62 \pm 0.18^{\mathrm{a}}$ & $0.41 \pm 0.04^{\mathrm{a}}$ \\
Average $\mathrm{N} / \mathrm{PO}_{4}^{3-}-\mathrm{P}$ molar ratio & 8.22 & 10.76 & $1.25 \pm 0.11^{\mathrm{b}}$ \\
\hline
\end{tabular}

${ }^{a}$ Influent of struvite plant (stripper inlet)

binfluent of crystallisation reactor (stripper outlet)

\section{RESULTS}

\section{Pilot-scale tests}

The anaerobic effluents from plants 1 and 3 were characterized by high phosphate levels (Table 1), with average $\mathrm{PO}_{4}^{3-}-\mathrm{P}$ concentrations above $110 \mathrm{mg}$ $\mathrm{PO}_{4}^{3-}-\mathrm{P} / \mathrm{L}$. In contrast, plant 2 showed significantly lower phosphate levels, between 38 to $52 \mathrm{mg} \mathrm{PO}_{4}^{3-}-\mathrm{P} / \mathrm{L}$. During the testing period, the operation of the full-scale UASB reactor was stable, resulting in effluent $\mathrm{pH}$ values of 7.00-7.85 and residual volatile fatty acid concentrations between 0.5 and $2.5 \mathrm{meq}$ acetic acid/L. Therefore, besides normal full-scale fluctuations, the composition of the UASB effluent remained constant during the testing period (Table 1).

The results obtained in the struvite pilot plant are summarized in Table 2.

Table 2. Effluent phosphate levels and phosphate removal efficiencies at the 3 test sites.

\begin{tabular}{lccc}
\hline & Plant 1 & Plant 2 & Plant 3 \\
\hline $\mathrm{PO}_{4}^{3-}-\mathrm{P}(\mathrm{mg} / \mathrm{L})$ & $12 \pm 3$ & $11 \pm 3$ & $103 \pm 11$ \\
Average $\mathrm{PO}_{4}^{3-}-\mathrm{P}$ removal (\%) & $89 \pm 3$ & $75 \pm 8$ & $19 \pm 8$ \\
Maximum $\mathrm{PO}_{4}^{3-}-\mathrm{P}$ removal (\%) & 95 & 88 & 31 \\
Minimum $\mathrm{PO}_{4}^{3-}-\mathrm{P}$ removal (\%) & 79 & 49 & 5 \\
\hline
\end{tabular}


High phosphate removal efficiencies were obtained in P1 and P2, with average values of $90 \%$ and $75 \%$, respectively. Moreover, despite the initial phosphate levels differed by a factor of 2.67 , similar concentrations were obtained in the effluent, around $10 \mathrm{mg} \mathrm{PO}_{4}^{3-}-\mathrm{P} / \mathrm{L}$. However, while the elimination remained constant in P1, P2 showed occasionally a limited efficiency not exceeding 50\%. Spherical self-retaining crystals of pure struvite, as confirmed by XRD analysis and with $98 \%$ of dry matter (after ambient temperature drying) were obtained in both plants. Heavy metal analysis only showed copper (21 mg Cu/kg dry matter) to be present in the struvite pellets of $\mathrm{P} 1$.

In contrast, low phosphate removal was noted in P3 (around 20\%). In addition, no struvite formation was observed at any conditions tested. The reason was probably the formation of amorphous calcium and/or magnesium phosphate flocculent matter. Detailed analysis of Ca levels in the influent and effluent of $\mathrm{P} 3$ showed Ca elimination of $9-26 \%$. A simple $\mathrm{pH}$ increase of the UASB effluent up to 8.30-8.50 was sufficient to initiate the amorphous sludge formation without $\mathrm{MgCl}_{2}$ addition. Addition of $\mathrm{MgCl}_{2}$ in the air stripping tank prior to $\mathrm{pH}$ adjustment in the crystallisation tank resulted in the formation of maiden orthorhombic pyramidal struvite crystals, which accumulated in the crystallisation tank. These smaller crystals, known as fines, could apparently not grow further, and thus not giving rise to spherical self-retaining crystals, such as those obtained in P1 and P2. Another difference was in the $\mathrm{NaOH}$ dose required to obtain the $\mathrm{pH}$ set-point. P3 needed a significantly lower amount $\left(0.08-0.20 \mathrm{~L} / \mathrm{m}^{3}\right)$ compared to the $\mathrm{NaOH}$ consumption in $\mathrm{P} 1\left(0.80-1.20 \mathrm{~L} / \mathrm{m}^{3}\right)$ and P2 $\left(0.50-1.00 \mathrm{~L} / \mathrm{m}^{3}\right)$.

The clear difference in the potential to produce struvite at the different tested plants can be probably explained by the varying $\mathrm{Ca}^{2+} / \mathrm{PO}_{4}^{3-}-\mathrm{P}$ ratios (Table 1). However, it should be noted that not only the $\mathrm{Ca}^{2+} / \mathrm{PO}_{4}^{3-}-\mathrm{P}$ molar ratio affects struvite formation, but also the absolute $\mathrm{Ca}^{2+}$ concentration. The $\mathrm{Ca}^{2+} / \mathrm{PO}_{4}^{3-}-\mathrm{P}$ molar ratio differed significantly between $\mathrm{P} 1$ and $\mathrm{P} 2$, while high phosphate removal efficiencies were obtained in both plants as well as similar struvite crystals. The reason is probably that no distinction in $\mathrm{Ca}^{2+}$ concentrations in the UASB effluent was noted, $40 \pm 8 \mathrm{mg} \mathrm{Ca}^{2+} / \mathrm{L}$ in $\mathrm{P} 1$ and $36 \pm 7 \mathrm{mg} \mathrm{Ca}^{2+} / \mathrm{L}$ in P2. P3 had clearly higher $\mathrm{Ca}^{2+}$ influent levels of $65 \pm 7 \mathrm{mg} \mathrm{Ca}^{2+} / \mathrm{L}$, which combined with the lower phosphate levels after the stripper (around $40 \mathrm{mg}$ $\left.\mathrm{PO}_{4}^{3-}-\mathrm{P} / \mathrm{L}\right)$, resulted in a $\mathrm{Ca}^{2+} / \mathrm{PO}_{4}^{3-}-\mathrm{P}$ molar ratio at the inlet of the crystallisation reactor of 1.25 (Table 1 ).

The $\mathrm{NH}_{4}^{+}-\mathrm{N}$ concentrations were not limiting at any of the examined sites. The $\mathrm{NH}_{4}^{+}-\mathrm{N} / \mathrm{PO}_{4}^{3-}-\mathrm{P}$ molar ratios in $\mathrm{P} 1, \mathrm{P} 2$ and $\mathrm{P} 3$ were 8.22, 10.76 and 4.54, respectively (Table 1). In terms of $\mathrm{NH}_{4}^{+}-\mathrm{N}$ concentrations, no difference was 
observed between P2 $\left(208 \pm 27 \mathrm{mg} \mathrm{NH} \mathrm{NH}_{4}^{+}-\mathrm{N} / \mathrm{L}\right)$ and P3 $(254 \pm 36 \mathrm{mg}$ $\mathrm{NH}_{4}^{+}-\mathrm{N} / \mathrm{L}$ ), while higher levels were present in $\mathrm{P} 1$ (426 $\left.\pm 45 \mathrm{mg} \mathrm{NH}_{4}^{+}-\mathrm{N} / \mathrm{L}\right)$.

More detailed data at $\mathrm{P} 1$ revealed that most soluble phosphate removal occurred in the crystallizer $(80 \%)$ and only a $20 \%$ decrease was noted in the stripper (Figure 2).

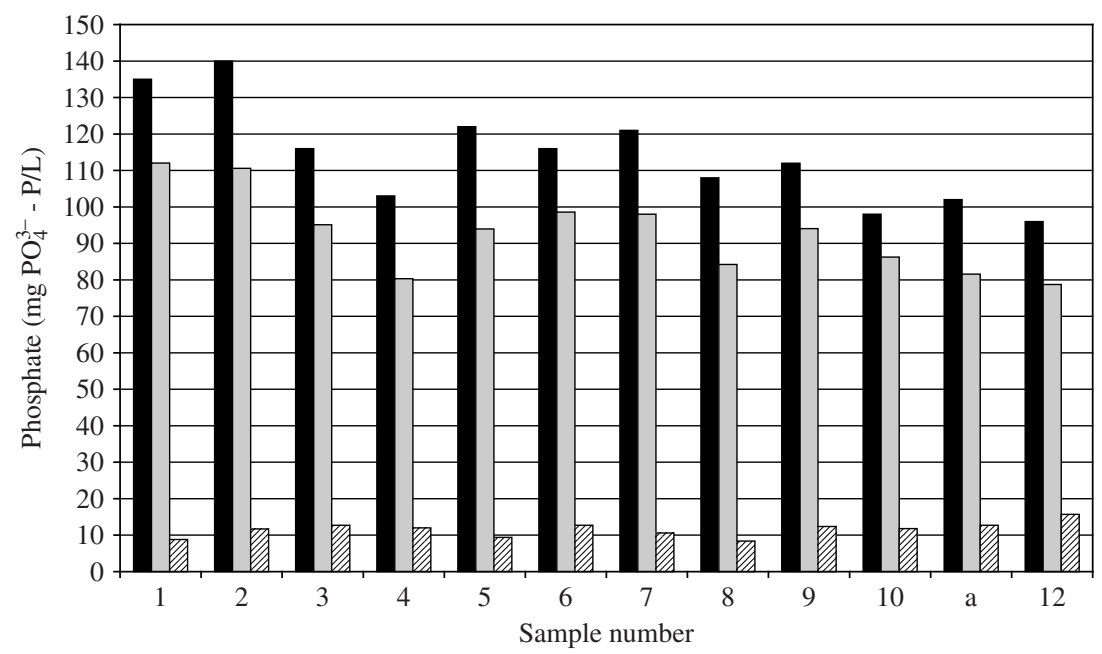

Figure 2. Orthophosphate levels in 12 samples taken during the pilot run in $\mathrm{P} 1$ Influent (black), air stripper (grey) and final effluent (striped).

The results shown in Figure 2 and Tables 1 and 2 refer to orthophosphate. After anaerobic treatment, around $90-95 \%$ of the total phosphorus was present as orthophosphate. Total phosphorus levels were analyzed once a week, approximately. In general, the total phosphorus effluent concentrations were 17 to $28 \%$ higher than the orthophosphate levels. Microscopic control of final effluent showed typical maiden orthorhombic fines in the effluent of P1 and P2.

\section{Full scale unit}

Based on the pilot tests, two full-scale units were designed and a process approach was developed, which is marketed as NuReSys ${ }^{\circledR}$ (Table 3). The main common features of both units are: air stripper, crystallisation reactor equipped with a top-entry mixer and a transient quiescent settling zone, $\mathrm{pH}$ control using $\mathrm{NaOH}$ and magnesium chloride as magnesium source.

The full-scale plant 1 contains a $200 \mathrm{~m}^{3}$ air-stripper and $125 \mathrm{~m}^{3}$ crystallisation reactor. The produced struvite crystals are retained in the tubular lamellae 
Table 3. Main characteristics of the full-scale NuReSys plants.

\begin{tabular}{cccc}
\hline & Average capacity & Operational characteristics & Status \\
\hline 1 & $100 \mathrm{~m}^{3} / \mathrm{h}$ & Dairy processing industry: & Operational \\
& $(192 \mathrm{~kg} \mathrm{P}$ total $/ \mathrm{d})$ & HRT* $^{*}: 25 \mathrm{~h}$ & \\
& & Footprint: $180 \mathrm{~m}^{2}$ & \\
2 & $60 \mathrm{~m}^{3} / \mathrm{h}$ & Potato processing industry & Start-up in October \\
& $(180 \mathrm{~kg} \mathrm{P}$ total $/ \mathrm{d})$ & HRT $^{*}: 2.23 \mathrm{~h}$ & 2008 \\
& & Footprint: $92 \mathrm{~m}^{2}$ & \\
\hline
\end{tabular}

*HRT: Hydraulic Retention Time.

settling zone located in the upper part of the crystallisation reactor and further purged towards a dewatering container by intermediate manual offset. These produced struvite crystals have been accredited for reuse in agriculture.

During the start-up of the plant, although a 70 to $75 \%$ decrease in phosphate was obtained, no struvite was produced due to similar $\mathrm{Ca}$ interference as observed during the pilot-scale tests at plant 3 . The calcium and phosphate levels in the UASB effluent of the dairy plant averaged $140 \mathrm{mg} \mathrm{Ca}^{2+} / \mathrm{L}$ and $40-45 \mathrm{mg}$ $\mathrm{PO}_{4}^{3-}-\mathrm{P} / \mathrm{L}$, resulting in an average $\mathrm{Ca}^{2+} / \mathrm{PO}_{4}^{3-}-\mathrm{P}$ molar ratio of 2.69. Moreover, no significant decrease of ammonia was observed during this period and a flocculent material was produced, as observed in the pilot-scale tests at P3. The produced amorphous matter contained mainly calcium, magnesium and phosphorus at a respective molar ratio of 2.50/0.75/1.80. Accordingly, $\mathrm{Ca}^{2+}$ concentrations decreased by $40-50 \%$. The flocculent matter was also produced in the stripper unit suggesting its production to be driven by $\mathrm{pH}$ increase. Changing the position of the inlet ports of alkaline reagent $\mathrm{NaOH}$ and $\mathrm{MgCl}_{2}$ to prevent the $\mathrm{pH}$-driven formation of the amorphous matter was not successful.

A batch experiment was performed with $2 \mathrm{~L}$ of full-scale UASB effluent spiked with concentrated $\mathrm{PO}_{4}^{3-}-\mathrm{P}$ solution to obtain a phosphate level of about $150 \mathrm{mg} \mathrm{PO}_{4}^{3-}-\mathrm{P} / \mathrm{L}$. After phosphate spiking, $\mathrm{pH}$ was adjusted and $\mathrm{Mg}^{2+}$ was added. Phosphate was removed from 145 to $14.7 \mathrm{mg} \mathrm{PO}_{4}^{3-}-\mathrm{P} / \mathrm{L}$. In addition, microscopic examination of the settled material clearly showed the formation of struvite crystals. Therefore, under these conditions corresponding to a $\mathrm{Ca}^{2+} /$ $\mathrm{PO}_{4}^{3-}-\mathrm{P}$ molar ratio of 0.77 , struvite formation was possible, but amorphous calcium/magnesium flocculent matter was still the main mechanism responsible for the phosphate decrease.

A gradual shift in UASB effluent due to an increase in phosphate concentrations up to an average of $69 \mathrm{mg} \mathrm{P}_{\text {total }} / \mathrm{L}$ resulted in a decrease of the $\mathrm{Ca}^{2+} / \mathrm{PO}_{4}^{3-}-\mathrm{P}$ molar ratio from 2.69 to 1.36 . The full-scale plant was operated under these conditions over a 23-week period and the results obtained are shown in Table 4. 
Table 4. Average, minimum and maximum phosphorus levels in the influent and effluent of the full-scale unit $(n=169)$.

\begin{tabular}{|c|c|c|c|c|}
\hline & \multirow{2}{*}{$\begin{array}{c}\text { Influent } \\
P_{\text {total }} \\
(\mathrm{mg} / \mathrm{L})\end{array}$} & \multicolumn{3}{|c|}{ Effluent } \\
\hline & & $\begin{array}{l}P_{\text {total }} \\
(\mathrm{mg} / \mathrm{L})\end{array}$ & $\begin{array}{c}P_{4}^{3-}-P \\
(m g / L)\end{array}$ & $\begin{array}{c}P_{\text {total }} \\
\text { removal (\%) }\end{array}$ \\
\hline Average & 64 & 14 & 9 & 78 \\
\hline Stand. Dev. & 13 & 4 & 3 & 7 \\
\hline Maximum & 108 & 33 & 26 & 91 \\
\hline Minimum & 38 & 7 & 4 & 38 \\
\hline
\end{tabular}

After the increase of phosphate influent levels, the formation of the flocculent amorphous matter has been largely suppressed and replaced by the growth of 2-6 $\mathrm{mm}$ in diameter spherical crystals struvite crystals (confirmed by XRD). The average ammonium influent levels during this period were $110 \pm 18 \mathrm{mg}$ $\mathrm{NH}_{4}^{+}-\mathrm{N} / \mathrm{L}$, resulting in a molar $\mathrm{NH}_{4}^{+}-\mathrm{N} / \mathrm{PO}_{4}^{3-}-\mathrm{P}$ ratio of 3.45 . Contrary to the start-up period, the phosphate removal was accompanied by an ammonium decrease of around $22 \mathrm{mg} \mathrm{NH}_{4}^{+}-\mathrm{N} / \mathrm{L}$, which would account for an average $46 \mathrm{mg}$ $\mathrm{PO}_{4}^{3-}-\mathrm{P} / \mathrm{L}$ immobilized as struvite. Taking into account the overall phosphate removal over the examined period, ca. $55 \mathrm{mg} \mathrm{PO}_{4}^{3-}-\mathrm{P} / \mathrm{L}$, the amorphous matter was responsible for only $16 \%$ of the total phosphate removal.

\section{DISCUSSION}

Results obtained at pilot-scale in plant 3 and during start-up of the full-scale plant 1 showed a negative interference of calcium. Pastor et al. (2007) observed a similar effect treating 2 anaerobic digestion liquors with $\mathrm{Ca}^{2+} / \mathrm{PO}_{4}^{3-}-\mathrm{P}$ molar ratios of 0.37 and 2.34, respectively. The high $\mathrm{Ca}^{2+} / \mathrm{PO}_{4}^{3-}-\mathrm{P}$ molar ratio liquor only removed $35 \%$ of the phosphorus as struvite, whilst the low $\mathrm{Ca}^{2+} / \mathrm{PO}_{4}^{3-}-\mathrm{P}$ molar ratio liquor achieved $73 \%$. Overall phosphorus removal efficiencies were as high as $83 \%\left(\right.$ ratio $\left.\mathrm{Ca}^{2+} / \mathrm{PO}_{4}^{3-}-\mathrm{P}=2.34\right)$ and $91 \%\left(\right.$ ratio $\left.\mathrm{Ca}^{2+} / \mathrm{PO}_{4}^{3-}-\mathrm{P}=0.37\right)$, indicating that phosphorus removal was partially attributed to amorphous calcium phosphate. Similarly, Le Corre et al. (2005) reported that $\mathrm{Ca}^{2+} / \mathrm{Mg}^{2+}$ molar ratios between 0.5 and 1.0 affected significantly struvite formation, and values exceeding 1 excluded nearly completely the formation of crystalline struvite. These findings are in accordance with the results obtained in this study, where $\mathrm{Ca}^{2+} / \mathrm{Mg}^{2+}$ molar ratios are nearly equal to the $\mathrm{Ca}^{2+} / \mathrm{PO}_{4}^{3-}-\mathrm{P}$ ratios since the $\mathrm{Mg}^{2+} / \mathrm{PO}_{4}^{3-}-\mathrm{P}$ molar ratio used was $1-1.2$. Full-scale results obtained at the average $\mathrm{Ca}^{2+} / \mathrm{PO}_{4}^{3-}-\mathrm{P}$ molar ratio of 1.36 are not in accordance with the 
limited struvite formation observed during the batch phosphate spiking test at $\mathrm{Ca}^{2+} / \mathrm{PO}_{4}^{3-}-\mathrm{P}$ of 0.77 . However, in order to compare these results rigorously, the differences in concentration profiles and mixing, and the presence of secondary nucleation surfaces need to be considered.

The use of top-entry mixers has been shown to be an alternative to fluidized bed systems for struvite formation (Pastor et al., 2008; Kim et al., 2008). The results obtained in this work confirm that this operational approach can be successfully applied, even at considerable high flow rates of $100-125 \mathrm{~m}^{3} / \mathrm{h}$. Furthermore, adjustable mixing rotary speed and flexible selection of reagent injection points are major advantages of this system (Mangin and Klein, 2004).

From mass balance calculations, it becomes obvious that not all of the phosphate is removed as struvite. Moreover, not the entire quantity of immobilized orthophosphate, either as struvite or as amorphous phosphate, is retained within the crystallisation reactor. The washed-out immobilized phosphates will be determinative in achieving the final effluent standards in terms of total phosphorus. Sperandio et al. (2008) have shown that the $\mathrm{pH}$ of activated sludge systems, influenced by nitrification/denitrification and aeration-driven stripping effect, is a major factor affecting the formation and conservation of crystalline phosphate compounds, and thus contributing to the overall phosphate removal efficiency.

The produced full-scale crystals were shown to be mainly composed of pure struvite. This fact confirms earlier reports related to the production of a high quality end product suitable for agricultural reuse (Miles and Ellis, 2001; Shu et al., 2006; Forrest et al., 2008).

\section{CONCLUSIONS}

1. Phosphate recovery by struvite formation is a high value added technique, mainly after anaerobic treatment as typically applied in the agro-industrial sector.

2. The interference of calcium is an important factor to be addressed, which could exclude the use of this technology.

3. Since the final $\mathrm{Ca}^{2+} / \mathrm{Mg}^{2+}$ molar ratios are a direct consequence of the initial $\mathrm{Ca}^{2+} / \mathrm{PO}_{4}^{3-}-\mathrm{P}$ molar ratios, the latter should be used as a determinative parameter instead of the $\mathrm{Ca}^{2+} / \mathrm{Mg}^{2+}$ molar ratios. The $\mathrm{Ca}^{2+} / \mathrm{PO}_{4}^{3-}-\mathrm{P}$ molar ratio should be low, preferably below 1.0.

4. Formation of amorphous calcium and magnesium phosphates may contribute to overall phosphate removal, but as a non-recoverable product. 
5. Feasibility of phosphate removal via struvite at high flowrates of $100-125 \mathrm{~m}^{3} / \mathrm{h}$ has been demonstrated without affecting the high efficiency.

6. The high-quality of the obtained struvite crystals indicates that minimal processing is required prior to reuse.

\section{REFERENCES}

Altinbas, M., Oztruk, I. and Aydin, A.F. (2002). Ammonium recovery from high strength agro industry effluents. Wat. Sci. \& Technol., 45, 189-196.

Battistoni, P., Fava, G., Pavan, P., Musacco, A. and Cecchi, F. (1997). Phosphate removal in anaerobic liquors by struvite crystallisation without addition of chemicals. Preliminary results. Water Res., 31, 2925-2929.

Battistoni, P., Boccadora, R., Fatone, F. and Pavan, P. (2005). Autonucleation and crystal growth of struvite in a demonstrative fluidized bed reactor (FBR). Environ. Tech., 26, 975-982.

Caffaz, S., Bettazzi, E., Scaglione, D. and Lubello, C. (2008). An integrated approach in a municipal WWTP: anaerobic codigestion of sludge with organic waste and nutrient removal from supernatant. Wat. Sci. and Technol., 58, 669-676.

Carballa, M., Moerman, W., De Windt, W., Grootaerd, H. and Verstraete, W. (2008). Strategies to optimize phosphate removal from industrial anaerobic effluents by magnesium ammonium phosphate (MAP) production. J. Chem. Technol. Biotechnol., doi: $10.1002 /$ jctb.2006.

Durrant, A.E., Scrimshaw, M.D., Stratful, I. and Lester, J.N. (1999). Review of the feasibility of recovering phosphate from wastewater for use as a raw material by the phosphate industry. Environ. Tech., 20, 749-758.

Doyle, J.D. and Parsons, S.A. (2004). Struvite scale formation and prevention. Wat. Sci. Technol., 49, 177-182.

Forrest, A.L., Fattah, K.P., Mavinic, D.S. and Koch, F.A. (2008). Optimizing struvite production for phosphate recovery in WWTP. J. Environ. Eng., 134, 395-402.

Gonzalez, P.R. and De Sa, M.E.G. (2007). Evaluation of struvite as a fertilizer: a comparison with traditional P sources. Agrochimica, 51, 301-308.

Greenberg, A.E., Clesceri, L.S. and Eaton, A.D. (2002). Standard Methods for the Examination of Water and Wastewater. American Public Health Association (APHA), Washington, DC.

He, S., Zhang, Y., Yang, M., Du, W. and Harada, H. (2007). Repeated use of MAP decomposition for the removal of high ammonium concentration from landfill leachte. Chemosphere, 66, 2233-2238.

Kim, D., Kim, J. Ryu, H.D. and Lee, S.I. (2008). Effect of mixing on spontaneous precipitation from semiconductor wastewater. Bioresource Technology, 100, 74-78. doi: $10.1016 /$ j.biortech.2008.05.024.

Laridi, R., Auclair, J.C. and Benmoussa, H. (2005). Laboratory and Pilot-scale phosphate and ammonium removal by controlled struvite precipitation following coagulation and flocculation of swine wastewater. Environ. Tech., 26, 525-536.

Le Corre, K.S., Valsami-Jones, E., Hobbs, P. and Parsons, S.A. (2005). Impact of calcium on struvite crystal size, shape and purity. J. Cryst. Growth, 283, 514-522. 
Li, X.Z. and Zhao, Q.L. (2002). MAP precipitation form landfill leachate and seawater bittern waste. Environ. Tech., 23, 989-1000.

Mangin, D. and Klein, J.P. (2004). Fluid dynamics concepts for a phosphate precipitation reactor design. In: Phosphorus in Environmental Technologies, principles and applications. Valsami-Jones, E., pp. 358-400, IWA Publishing.

Milles, A. and Ellis, T.G. (2001). Struvite precipitation potential for nutrient recovery from anaerobically treated wastes. Wat. Sci. \& Technol., 43, 259-266.

Ohlinger, K.N., Young, T.M. and Schroeder, E.D. (1998). Predicting struvite formation in digestion. Water Res., 32, 3607-3614.

Pastor, L., Marti, N., Bouzas, A. and Seco, A. (2007). Calcium effect on struvite crystallization of liquors from an anaerobic digestion of prefermented and EBPR sludge. Proceedings of Nutrient Removal 2007: state of the art, 4-7 March 2007, Baltimore, USA, 136-144.

Pastor, L., Mangin, D., Barat, R. and Seco, A. (2008). A pilot-scale study of struvite precipitation in a stirred tank reactor: conditions influencing the process. Bioresour. Technol., doi: 10.1016/j.biortech.2007.12.003.

Shu, L., Schneider, P., Jegatheesan, V. and Johnson, J. (2006). An economic evaluation of phosphorus recovery as struvite from digester supernatant. Bioresour. Technol., 97, 2211-2216.

Stefanowicz, T., Napieralska-Zagozda, S., Osińska, M. and Samsonowska, K. (1992). Ammonium removal from waste solutions by precipitation of $\mathrm{MgNH}_{4} \mathrm{PO}_{4}$ II. Ammonium removal and recovery with recycling regenerate. Resour. Conservat. Recycl., 6, 339-345.

Sperandio, M., Pambrun, V. and Paul, E. (2008). Simultaneous removal of N and P is SBR with production of valuable compounds: application to concentrated wastewaters. Wat. Sci. \& Technol., 58, 859-864.

Ueno, Y. and Fujii, M. (2001). Three years experience of operating and selling recovered struvite from full-scale plant. Environ. Tech., 22, 1373-1381.

von Munch, E. and Barr, E. (2001). Controlled struvite crystallisation for removing phosphorus from anaerobic digester side streams. Water Res., 35(1), 151-159.

Williams, S. (1999). Struvite precipitation in the sludge stream at Slough wastewater treatment plant opportunities for phosphorus recovery. Environ. Tech., 20, 743-747. 